\title{
The Relationship between Self-Concept and Self-Ratings of Generalizable Skills of Students in Postsecondary Career and Technical Programs
}

\author{
Sharon L. Kraebber, Ph.D. \\ James P. Greenan, Ph.D. \\ Purdue University
}

Increasingly, employers desire skills that have traditionally been the purview of high schools and postsecondary career and technical training systems: reading and writing, applied mathematics, and technical and functional skills specific to an occupational area. However, employers also want employees to possess generic skills, employability skills, essential skills, and applied general education skills. These include knowing how to learn, interpersonal skills (e.g., teamwork, leadership, customer service, negotiation), competence in applying general education (e.g., reading, writing, calculating, computing) to workplaces, effective listening and oral communication skills, information gathering and analysis, problem solving, critical/creative thinking, organizing, planning, decision-making, and personal attributes (e.g., motivation, integrity, dependability, self-management). Many of these skills were once reserved for those in management; however, they now are considered necessary for individuals at all levels (Boyette \& Conn, 1991; Carnevale, Gainer, \& Meltzer, 1990; Coplin, 2003; Gardner, 2004; Lynch, 2000; Nedrow, 2002; Pearlman, 1997; Resnick, 1997; Secretary’s Commission on Achieving Necessary Skills [SCANS], 1991).

Career and technical education prepares the learner for entry into a particular occupation or family of occupations. Moreover, career and technical education is concerned with upgrading workers' skills (Wenrich, Wenrich, \& Galloway, 1988). These programs should focus on those skills that are necessary and transferable between and among educational and occupational settings (Carnevale et al., 1990). Research in the mid-1980s indicated that outstanding employees differ from their less able colleagues in their ability to critically determine what is needed on the job and then to apply those abilities to complete their necessary tasks costeffectively (Mikulecky, 1987).

Generic workplace readiness begins with the concept of generalizable skills. Generalizable skills are basic to, necessary for success in, and transferable within and/or across career and technical programs and occupations (Greenan, 1983, 1986). Generalizable mathematics, communications, interpersonal, and reasoning skills are important for students to attain to enter and succeed in the workforce (Greenan, 1983, 1984, 1986, 1988; Greenan \& Winters, 1989).

A positive self-concept is important for all individuals. Self-concept is a person's ideas or perceptions about one's self (Dembo, 1994). Super (1963) contended that self-concept is tied to career choice as well as entry into and success in the workforce. Essential within Super's theory is that, in making a career choice, an individual is expressing his or her self-concept. Therefore, it is crucial that students have accurate knowledge about themselves, or they may choose careers that do not match well with their interests, skills, and abilities (Super, 1963). 
Numerous studies have investigated the effects of self-concept on career success (Greenan, 1983, 1986; Greenan \& Sitlington, 1987; Greenan \& Winters, 1989). Research by Bourn (1976), which focused on the significant relationship between self-esteem and academic achievement, strongly suggested that instructors cannot and should not ignore the self-concept of the student. Accurate assessments of students' generalizable skills and self-concept are essential for appropriate placement, individualized planning, curriculum development and revision, and instructional decisions (Greenan, 1988; Greenan \& Winters, 1989). Accordingly, students' selfconcept and self-ratings of generalizable skills instruction and research are important considerations in the conceptual framework of career and technical education (see figure 1).

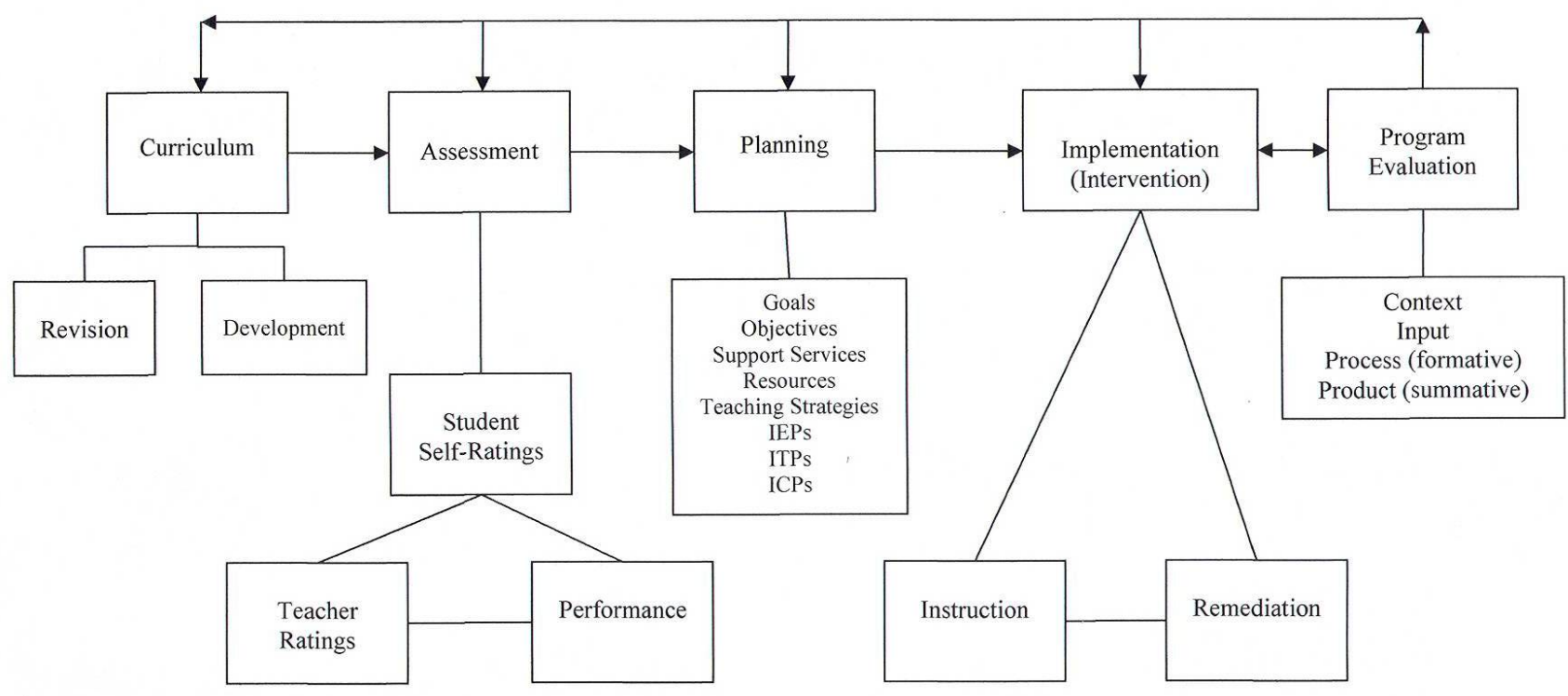

Figure 1: Conceptual Framework: Generalized Skills Instruction and Research (J. Greenan, personal communication, April 30, 2011)

Previous research (Greenan 1984, 1986, 1988; Greenan \& McCabe, 1989; Greenan \& Sitlington, 1987; Greenan \& Winters, 1989; Loeding \& Greenan, 1999) has suggested that selfratings of students' generalizable mathematics, communications, interpersonal relations, and reasoning skills possess high face and content validity and moderate to high reliability with internal consistency reliability coefficients $r \geq 0.60$ for the general career and technical education student population as well as for students with disabilities. Greenan, Wu, Munn, and Robson's (1994) study revealed low correlations between student self-ratings and self-concept in the four generalizable skills areas. However, the population was career and technical students at the 
secondary school level. Wu, Chenghsien, Greenan, and Mustapha (2002) investigated reasoning skills among career and technical college students in Taiwan. Additional research with other populations and samples needs to be conducted to further examine the relationship between generalizable skills student self-ratings and self-concept.

The purpose of this study was, therefore, to determine the relationship between selfconcept and self-ratings of generalizable skills of adult students in postsecondary career and technical programs. The following research questions were posited for this study:

1. Is there a relationship between students' self-concept and self-ratings of generalizable skills for all students?

2. Is there a relationship between students' self-concept and self-ratings of generalizable skills by gender, age, years of education, or ethnicity?

3. Is there a relationship between students' self-concept and self-ratings of generalizable skills by career and technical program?

This study was an examination of the association between the constructs of self-ratings and self-concept. It is expected that the data and information will contribute to the knowledge base and improve practice by assisting researchers and instructional personnel to better understand and use student assessment information in postsecondary career and technical programs. If self-ratings are found to correlate highly with self-concept, then it may provide some additional evidence to support the theory that self-ratings may actually measure student self-concept. However, low correlations might suggest that self-ratings measure a theoretical construct other than self-concept.

\section{Methodology}

\section{Population and Sample}

The population for this study was all postsecondary career and technical education students in one Midwestern state. One two-year career and technical college representative of a variety of students, teachers, and programs was selected to participate in the study. Upper level degree track courses were selected in an effort to avoid duplication within and across programs. Entire classes were selected purposively from the four career and technical program areas (e.g., business, health, family and consumer sciences, and industrial/technology programs). Program areas with initial enrollments of 50-60 students were used to achieve an $n$ of 175 students. Two programs had a total of less than 40 students enrolled (36 in industrial/technology and 34 in family and consumer sciences) and were, therefore, selected in their entirety. Enrollments in business and health classes each had in excess of 60 students. Random selection of subjects was performed to obtain a comparable sample of approximately 40 students for both the business and health programs. All subjects were informed about the study and their participation was strictly voluntary based on their informed consent.

The sample design was based on official enrollment data obtained at the end of the first week of the spring semester. The business program area was comprised of classes in office 
administration, accounting, and business administration. Human services and practical nursing classes represented the health and human services program. Early childhood education was the only class from the family and consumer sciences program area. Two electronics courses in the technical/industrial program were included in the sample. Due to attrition, poor attendance, and a clinical rotation during the 14th week of the semester, a total of 90 students participated in this study.

\section{Instrumentation}

The instruments used in this study included the Generalizable Skills Student Self-Ratings Assessment and the Tennessee Self-Concept Scale: Second Edition (Fitts \& Warren, 1996). These two instruments were administered to all of the pilot and field study subjects. Self-Ratings Assessment instruments (Barker, 2004; Greenan, 1982, 1983, 1984, 1986, 1988, 1994; Greenan \& McCabe, 1989; Greenan \& Winters, 1989; Wu et al. 2002; Wu \& Greenan, 2003) were used in this study. The intent of these instruments was to measure generalizable mathematics, communications, interpersonal relations, and reasoning skills using self-ratings reports.

The Generalizable Mathematics Skills Self-Ratings Assessment instrument was developed by Greenan (1984) to assess how well students could estimate their generalizable mathematics skills. The instrument contains 28 Likert-type items and is composed of the following seven scales: (a) whole numbers scale, (b) fractions scale, (c) decimals scale, (d) percent scale, (e) mixed operations scale, (f) measurement and calculation scale, and (g) estimation scale. The student self-ratings instrument possesses high internal consistency reliability (Cronbach's coefficient alpha $=0.96)$ and test-retest reliability $(r=0.81, p<.001)$.

Greenan (1988) also developed the Generalizable Communications Skills Assessment instrument to assess how well students perceive their generalizable communication skills. This instrument includes 27 Likert-type items within the following five scales: (a) words and meanings scale, (b) reading scale, (c) writing scale, (d) speaking scale, and (e) listening scale. The instrument possesses high internal consistency reliability (Cronbach's coefficient alpha $=0.93)$ and test-retest reliability $(\mathrm{r}=0.81, \mathrm{p}<.001)$.

Greenan and Winters (1989) developed the Interpersonal Relations Skills Assessment instrument to measure students' perceptions of their own interpersonal relations skills. This instrument includes 20 Likert-type items in the following three scales: (a) work behaviors, (b) instructional and supervisory conversations, and (c) social conversations. This instrument possesses high internal consistency reliability (Cronbach's coefficient alpha $=0.89)$ and moderate test-retest reliability of $\mathrm{r}=0.60(\mathrm{p}<.001)$.

Greenan and McCabe (1989) developed the Generalizable Reasoning Skills instrument for student self-ratings to assess students' perceptions of their reasoning skills. This instrument consisted of the following three scales: (a) verbal reasoning, (b) problem solving, and (c) planning. These instruments possess high internal consistency reliability (Cronbach's coefficient alpha $=0.94)$ and moderate test-retest reliability of $r=0.67(p<.001)$. 
Each of the instruments uses a 4-point Likert-type scale $(1=$ cannot do, $2=$ cannot do well, $3=$ can do fairly well, and $4=$ can do well) to record students' self-ratings. An open-ended comments section is located after the self-rating for each skill area. These instruments have been validated in career and technical programs and typically have internal consistency reliability coefficients greater than 0.90 (Greenan 1984, 1986, 1988; Wu \& Greenan, 2003).

The test-retest reliability of $r=0.81$ (Pearson Product-Moment Correlation Coefficient) for the total Student Self-Ratings instrument indicates that the Student Self-Ratings instrument is capable of producing stable results. The test-retest reliability coefficients typically range from 0.70 to 0.99 for career and technical programs. The coefficient for male students was 0.66 and 0.88 for female students (Wu \& Greenan, 2003).

\section{Tennessee Self-Concept Scale: Second Edition}

The revised 1998 edition of the Tennessee Self-Concept Scale: Second Edition (TSCS:2) was used in the study. The TSCS:2 was selected because it was developed and validated using adolescent and adult school populations. The TSCS:2 has been recognized for more than 30 years as a widely validated self-assessment instrument to measure self-concept that possesses adequate psychometric properties (Fitts \& Warren, 1996). The TSCS:2 was developed to assist researchers in obtaining knowledge about the relationship between self-concept and human behavior. The basic scores are two Summary Scores, Total Self-Concept and Conflict, and six Self-Concept Scales:

(a) Physical, (b) Moral, (c) Personal, (d) Family, (e) Social, and (f) Academic/Work self. The TSCS:2 yields four Validity Scores: (a) Inconsistent Responding, (b) Self-Criticism, (c) Faking Good, and (d) Response Distribution. There are also three Supplementary Scores that reflect the original theoretical intent of the test. They are Identity, Satisfaction, and Behavior. The TSCS: 2 consists of 82 items. Although the TSCS:2 has been shortened from the original version, the retained scores are psychometrically equivalent to those in the 1988 edition (Fitts \& Warren, 1996).

The TSCS: 2 has been found to produce reliable and valid results. The Adult Form scores have yielded high internal consistency ranging from 0.73 to 0.95 (median 0.80 ). The test-retest reliability coefficients for the TSCS:2 ranged from 0.47 to 0.82 . These values are somewhat lower than the 1988 TSCS values due to shortened item sets (Fitts \& Warren, 1996).

The examination of validity involves determining the extent to which an assessment actually measures those characteristics that it claims to measure in a meaningful and useful way. The TSCS: 2 was determined to possess an adequate degree of construct validity. It is considered valid when compared to other accepted psychological instruments and when distinguishing among various groups (Fitts \& Warren, 1996).

A pilot study was conducted for the purposes of validating and refining the administration procedures in the research environment. A convenience sample of 83 students, selected from postsecondary career and technical programs, completed the Generalizable Skills Student Self-Ratings Assessment instruments and the TSCS:2. The sample was derived from classes of students whose instructors had agreed to participate. The correlations between the 
student self-ratings on the Generalizable Skills Assessment instruments and the TSCS:2 were derived by course descriptor, gender, and ethnicity. The correlations between student selfratings on the Generalizable Mathematics Skills Assessment and the TSCS:2 were determined by course descriptor (health occupations $r=0.45$, accounting $r=0.18$, industrial occupations $r=$ 0.12 , medical technology $r=0.00$, and introduction to business $r=-0.10$ ). The overall correlation between the two instruments was $-0.201(\mathrm{n}=77, \mathrm{p}<.001)$. In general, the correlations contained some statistical, but no practical significance. This indicated that minimal variance was explained between measures of self-reports and self-concept. Additionally, the instruments and procedures were judged to have an adequate degree of content and face validity.

\section{Data Collection}

The data were collected at the postsecondary career and technical college during a time of convenience for the college and its programs. Data collection occurred during a one-week period during regularly scheduled class times. The availability of subjects varied by program; therefore, the data collection was conducted during optimal availability of the subjects. Subject participation was strictly voluntary. The researcher administered the Generalizable Skills Student Self-Ratings Assessment instruments and the TSCS:2. Each student completed the four Generalizable Skills Student Self-Ratings Assessment instruments followed by the TSCS:2.

\section{Data Analysis}

The quantitative data were coded and scored using summated ratings, and then analyzed using Microsoft Excel. Pearson Product-Moment Correlation coefficients were computed by program, gender, age, years of education, ethnicity, degree, and program area. The qualitative data were obtained from the open-ended responses. Responses from different subjects were grouped according to responses by generalizable skill area, then according to common themes that emerged. The data for each skill area were analyzed, synthesized, and summarized using cross-case analysis (Marshall \& Rossman, 1999; Patton, 2002).

\section{Results}

The Generalizable Skills Student Self-Ratings Assessments were designed to assess students' perceptions of their skills. Previous research suggested that self-ratings are likely measuring a construct or constructs that are different than those intended to be measured by existing criterion measures. Accordingly, self-concept was perceived to be a construct related to self-ratings.

Research Question 1: Is there a relationship between students' self-concept and selfratings of generalizable skills for all students?

Ninety students completed the instruments with 83 being judged usable. Missing pages or a preponderance of missing information were the reasons for judging instruments to be incomplete and unusable. Therefore, there was a 92.2 percent usability rate. Both instruments possess high internal consistency reliability as determined by Cronbach's coefficient alpha of 0.90 for the student self-ratings instrument and 0.71 for the TSCS:2. For all students across programs, the results revealed low correlations between student self-concept and self-ratings for 
the four generalizable skill areas (see Table 1). The correlations (Pearson's r) ranged from -0.12 to 0.07 for mathematics skills, -0.03 to -0.23 for communication skills, -0.08 to 0.07 for interpersonal skills, and -0.18 to 0.03 for reasoning skills. The correlations between the two instruments were -0.04 for mathematics skills, -0.21 for communication skills, -0.03 for interpersonal relations skills, and -0.13 for reasoning skills. The only statistically significant correlation was communication skills self-ratings with the moral-ethical subscale of self-concept of the TSCS:2 $(\mathrm{r}=0.23, \mathrm{p}<.05)$. Negative correlations between the two instruments were noted with 24 of 28 correlations being negative. For the entire sample, more than $95.5 \%$ of the variance between generalizable skills self-ratings and TSCS:2 self-concept was unexplained. The internal consistency reliability for each of the four Generalizable Skills instruments is extremely strong for the post-secondary data collected. The Chronbach's Alpha for the mathematics instrument is 0.981 , for communication 0.988 , for interpersonal skills 0.993 and for reasoning 0.968 .

The lack of statistically significant correlations between the four generalizable skills areas appears to indicate minimal relationships between self-ratings and self-concept. The generalizable skills assessment instrument sub-divided self-concept into four specific skill areas (e.g., mathematics, communications, interpersonal relations, and reasoning skills), while the TSCS: 2 focused on self-concept, interpersonal and social relations, and academic and work situations. The low correlations may suggest that the Generalizable Skills Self-Ratings instruments were not measuring the construct of self-concept.

Table 1

Correlations Between Generalizable Skills Self-Ratings and TSCS:2 for All Students

\begin{tabular}{lcccc}
\hline \multicolumn{5}{c}{ Generalizable Skills } \\
\hline TSCS:2 & Mathematics & Communication & Interpersonal & Reasoning \\
\hline Physical & -0.01 & -0.15 & -0.04 & -0.05 \\
Moral - & & & & \\
Ethical & -0.06 & $-0.23^{*}$ & 0.00 & -0.18 \\
Personal & -0.12 & -0.21 & -0.08 & -0.13 \\
Family & -0.04 & -0.06 & 0.07 & 0.03 \\
Social & 0.01 & -0.15 & -0.01 & -0.16 \\
Academic & 0.07 & -0.03 & -0.08 & -0.02 \\
& & & & -0.13 \\
\hline
\end{tabular}

$* \mathrm{p}<0.05$

$\mathrm{n}=83$

Research Question 2: Is there is a relationship between students' self-concept and selfratings of generalizable skills by gender, age, years of education, or ethnicity?

Of the 90 students completing the self-ratings and self-concept instruments, 19 were male and 71 were female (see Table 2). Overall, males had higher and more statistically significant correlations between generalizable skills self-ratings and TSCS:2 than females. The exception 
was mathematics skills self-ratings where the overall correlation was 0.03 for females and -0.50 for males.

For mathematics skills, the males had an overall correlation with the TSCS: 2 of $\mathrm{r}=-0.50, \mathrm{p}<0.05$, while other scales that revealed statistical significance were moral, $\mathrm{r}=-0.63$, $\mathrm{p}<.01$, personal, $\mathrm{r}=-0.53, \mathrm{p}<.05$, and academic, $\mathrm{r}=-0.54 . \mathrm{p}<.05$. The females had correlations ranging from -0.01 to 0.19 for the six TSCS: 2 scales and $r=0.03$ for the overall correlation; however, none were statistically significant.

For communication skills, the overall correlation for females was $r=-0.28, p<.05$, while other TSCS: 2 scales with statistical significance $(p<.05)$ were personal, $r=-0.28$ and family, $r=-0.27$. The correlations for the remaining scales for females ranged from -0.22 to -0.08 . The males had more positive correlations; however, none were statistically significant, ranging from -0.35 to .45 with an overall correlation of $r=0.14$.

The findings revealed weak to moderate correlations between generalizable skills selfratings and TSCS: 2 for gender. The highest correlation was -0.50 (overall mathematics selfratings for males). The coefficient of determination $\left(\mathrm{r}^{2} \times 100\right)$ indicated that only $25 \%$ of the variance was accounted for between generalizable skills self-ratings and self-concept. That is, for both males and females, $75 \%$ of the variance was unexplained.

These data did not reveal that a difference in gender affected students' self-concept. The findings appear inconsistent with those of Greenan et al. (1994), Skaalvik and Rankin (1990), and Lunscombe and Riley (2001). Additionally, Skaalvik and Rankin (1990) revealed that verbal self-concept had a direct and significant effect on the general academic self-concept of female students, while mathematics self-concept had a similar effect on male students. The difference in correlations among the four Generalizable Skill areas may or may not be caused by the varying expectations between genders or the effects of gender stereotypes on self-concept (Greenan et al., 1994).

Table 2

Correlations Between Generalizable Skills Self-Ratings and TSCS:2 by Gender

Generalizable Skills

\begin{tabular}{lcccccccc}
\hline & \multicolumn{2}{c}{ Mathematics } & \multicolumn{2}{c}{ Communications } & \multicolumn{2}{c}{ Interpersonal } & \multicolumn{2}{c}{ Reasoning } \\
\hline TSCS:2 & $\mathrm{M}$ & $\mathrm{F}$ & $\mathrm{M}$ & $\mathrm{F}$ & $\mathrm{M}$ & $\mathrm{F}$ & $\mathrm{M}$ & $\mathrm{F}$ \\
\hline Physical & 0.14 & -0.11 & 0.29 & -0.22 & 0.25 & -0.10 & $.049^{*}$ & -0.16 \\
Moral & $-0.63^{* *}$ & 0.10 & -0.35 & -0.18 & -0.06 & 0.02 & -0.20 & -0.17 \\
Personal & $-0.53^{*}$ & -0.07 & 0.10 & $-0.28^{*}$ & 0.11 & -0.13 & 0.12 & -0.19 \\
Family & 0.00 & 0.03 & 0.45 & $-0.27^{*}$ & 0.21 & 0.02 & 0.34 & -0.07 \\
Social & 0.04 & -0.01 & -0.29 & -0.11 & 0.19 & -0.07 & -0.34 & -0.12 \\
Academic & $-0.54^{*}$ & 0.19 & 0.21 & -0.08 & -0.01 & -0.09 & 0.07 & -0.04 \\
& & & & & & & & \\
TOTAL & $-0.50^{*}$ & 0.03 & 0.14 & $-0.28^{*}$ & 0.25 & -0.08 & 0.16 & -0.18 \\
\hline
\end{tabular}


Note $: \mathrm{N}=18 ; \quad \mathrm{M}=$ male $\mathrm{N}=68 ; \mathrm{F}=$ female

$* \mathrm{p}<.05 \quad * * \mathrm{p}<0.01$

Only 65 of the 83 students completing the Generalizable Skills Self-Ratings instrument and the Tennessee Self-Concept Scale provided their ages. They ranged in age from 19 to 54 years of age with a mean of 29.7 years. Four age ranges were determined. There were four participants younger than 20 years of age, 37 in the 20-29 range, 13 in the 30-39 range, and 11 older than 39.

Overall correlations for the age groups ranged from -0.43 to -0.12 for reasoning skills (see Table 3). For the youngest students, correlations across TSCS:2 scales ranged from -0.92 to 0.65 . For the 20-29 year age group, correlations ranged from -0.24 to 0.02 . A statistically significant $(p<.05)$ correlation for students between 30 and 39 was $r=-0.63$, for the TSCS:2 family scale. The remaining five scales had correlations ranging from -0.5 to -0.01 for this age group. Those students who were older than 39 revealed no statistically significant correlations; however, they did range from -0.49 to -0.03 for the six TSCS: 2 scales.

The results reported, in some cases, nearly no correlation $(r=0.00)$, to $r=0.99$, within the self-concept scales. Overall, the results indicated low to moderate correlations between student self-ratings and self-concept by age group. The coefficient of determination for the highest correlation, $r=-0.52$ (for the $30-39$ age range, interpersonal skills) was $27 \%$. That is, $73 \%$ of the variance between student self-concept and self-ratings was unexplained.

Seventy-eight of the 83 students provided information regarding their years in education (see Table 4). Students reported that they had attended school between 9 and 17 years. The mean for years of education was 14.12. For statistical analysis purposes, years of education grouped students into five categories: less than $13,13,14,15$, and greater than 15 years.

Table 3

Correlations between Generalizable Skills Self-Ratings and TSCS:2 by Age

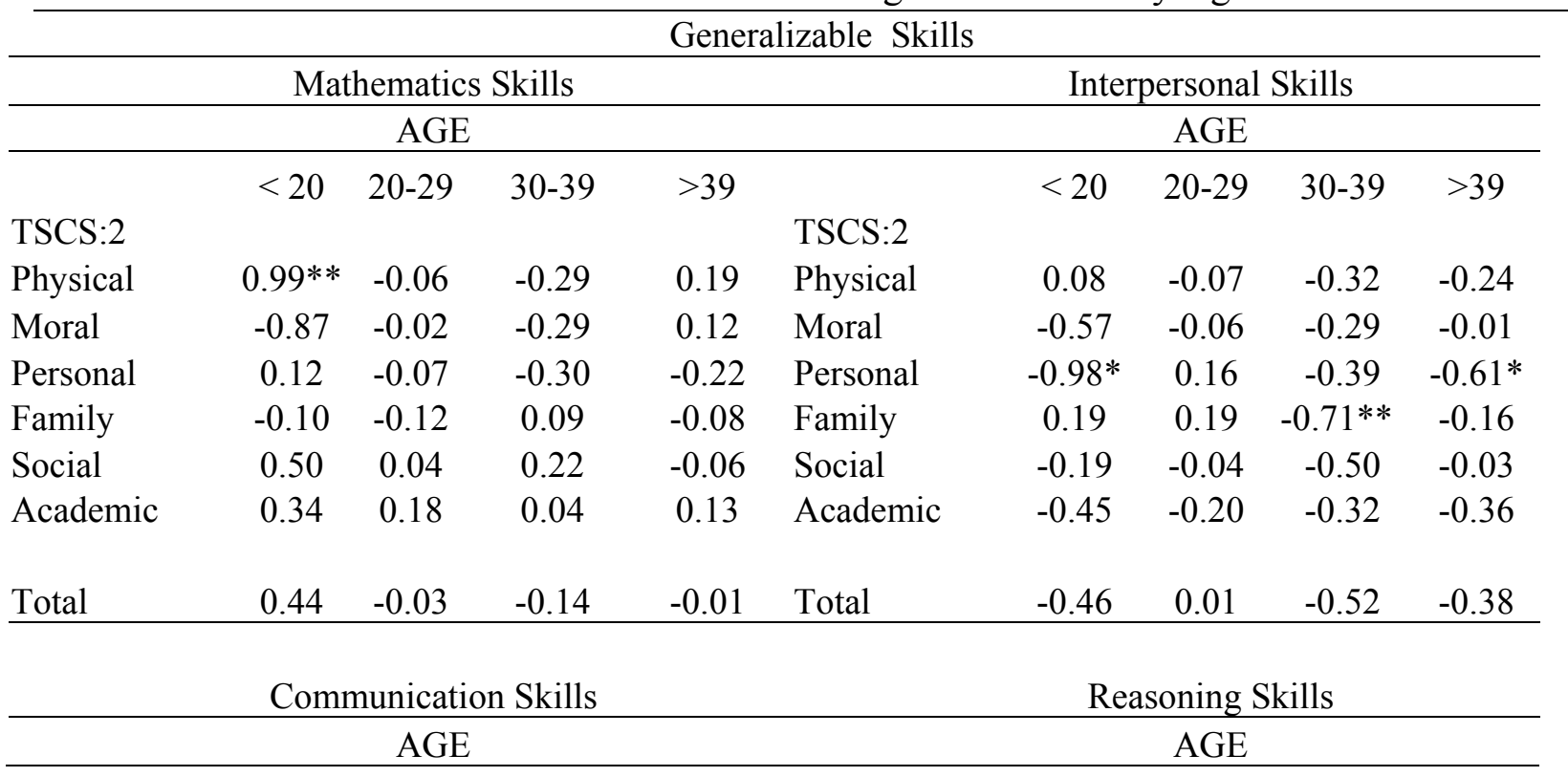




\begin{tabular}{lcccclcccc}
\hline & $<20$ & $20-29$ & $30-39$ & $>39$ & & $<20$ & $20-29$ & $30-39$ & $>39$ \\
Physical & $0.98^{*}$ & 0.08 & $-0.62^{*}$ & -0.43 & Physical & 0.65 & 0.02 & -0.50 & -0.38 \\
Moral & -0.90 & -0.08 & -0.41 & -0.36 & Moral & -0.92 & -0.11 & -0.25 & -0.49 \\
Personal & -0.01 & -0.12 & -0.21 & -0.43 & Personal & -0.53 & 0.02 & -0.32 & -0.28 \\
Family & 0.16 & -0.22 & -0.39 & 0.36 & Family & -0.37 & -0.03 & $-0.63^{*}$ & -0.03 \\
Social & 0.63 & -0.13 & -0.01 & $-0.68^{*}$ & Social & -0.13 & -0.16 & -0.31 & -0.55 \\
Academic & 0.43 & -0.19 & -0.01 & 0.36 & Academic & -0.38 & -0.24 & -0.01 & -0.40 \\
& & & & & & & & & \\
Total & 0.51 & -0.16 & -0.36 & -0.26 & Total & -0.29 & -0.12 & -0.43 & -0.37 \\
\hline
\end{tabular}

Note: $\mathrm{N}=4,<20 ; \mathrm{N}=37,20-29 ; \mathrm{N}=13,30-39, \mathrm{~N}=11,>39$

$* \mathrm{p}<0.05 * * \mathrm{p}<0.01$

Table 4

Correlations Between Generalizable Skills Self-Ratings and TSCS:2 by Years of Education

\begin{tabular}{|c|c|c|c|c|c|c|c|c|c|c|c|}
\hline \multicolumn{7}{|c|}{ Mathematics Skills } & \multicolumn{5}{|c|}{ Interpersonal Skills } \\
\hline & \multicolumn{5}{|c|}{ Years of Education } & & \multicolumn{5}{|c|}{ Years of Education } \\
\hline & $<13$ & 13 & 14 & 15 & $>15$ & & $<13$ & 13 & 14 & 15 & $>15$ \\
\hline TSCS:2 & & & & & & TSCS:2 & & & & & \\
\hline Physical & -0.52 & -0.43 & 0.23 & 0.06 & 0.32 & Physical & -0.14 & -0.46 & 0.15 & -0.45 & 0.21 \\
\hline Moral & -0.31 & 0.17 & -0.06 & -0.20 & 0.50 & Moral & -0.17 & -0.01 & 0.12 & -0.13 & 0.19 \\
\hline Personal & 0.06 & -0.11 & -0.07 & -0.46 & $0.56^{*}$ & Personal & 0.46 & -0.23 & -0.24 & -0.16 & $0.66^{*}$ \\
\hline Family & 0.07 & 0.59 & -0.15 & 0.17 & 0.05 & Family & 0.56 & 0.13 & 0.02 & -0.07 & 0.04 \\
\hline Social & 0.24 & 0.00 & 0.02 & 0.05 & 0.16 & Social & 0.04 & -0.13 & 0.09 & -0.28 & 0.10 \\
\hline Academic & -0.30 & 0.09 & 0.16 & 0.00 & 0.36 & Academic & $-0.78 *$ & -0.09 & 0.06 & -0.11 & 0.38 \\
\hline Total & -0.38 & 0.08 & 0.03 & -0.13 & 0.50 & Total & -0.08 & -0.19 & 0.07 & -0.31 & 0.40 \\
\hline \multicolumn{7}{|c|}{ Communication Skills } & \multicolumn{5}{|c|}{ Reasoning Skills } \\
\hline \multicolumn{7}{|c|}{ Years of Education } & \multicolumn{5}{|c|}{ Years of Education } \\
\hline & $<13$ & 13 & 14 & 15 & $>15$ & & $<13$ & 13 & 14 & 15 & $>15$ \\
\hline Physical & -0.36 & -0.36 & -0.06 & 0.10 & 0.24 & Physical & -0.27 & $-0.65^{*}$ & 0.17 & -0.16 & 0.48 \\
\hline Moral & -0.32 & -0.33 & -0.20 & -0.10 & 0.17 & Moral & -0.28 & -0.49 & -0.02 & -0.19 & 0.33 \\
\hline Personal & 0.24 & -0.08 & $-0.36^{*}$ & -0.36 & 0.29 & Personal & 0.35 & -0.10 & -0.02 & -0.24 & 0.31 \\
\hline Family & 0.26 & 0.17 & 0.12 & 0.03 & -0.08 & Family & 0.45 & -0.13 & 0.12 & -0.10 & 0.06 \\
\hline Social & 0.35 & -0.09 & -0.30 & -0.05 & 0.19 & Social & 0.24 & -0.28 & -0.09 & -0.45 & 0.10 \\
\hline Academic & -0.37 & 0.08 & -0.12 & -0.04 & 0.42 & Academic & $-0.71^{*}$ & 0.02 & 0.17 & -0.04 & 0.37 \\
\hline Total & -0.20 & -0.15 & -0.25 & -0.14 & 0.35 & Total & -0.18 & -0.33 & 0.05 & -0.35 & 0.46 \\
\hline
\end{tabular}

Note: $\mathrm{N}=8,<13$ yrs; $\mathrm{N}=11,13 \mathrm{yrs} ; \mathrm{N}=31,14 \mathrm{yrs} ; \mathrm{N}=14,15 \mathrm{yrs} ; \mathrm{N}=14,>15$ yrs

$* \mathrm{p}<0.05$ 
Years of education appeared to have a positive impact on the correlation between selfreports and self-concept. It also appears that those individuals with more than 15 years of education revealed the greatest overall correlation between self-reports and self-concept. Students with less than 13 years of education had statistically significant negative correlations with the TSCS:2 academic scale and both interpersonal and reasoning skills self-reports. The TSCS:2 personal scale had a statistically significant correlation with mathematics and interpersonal skills self-ratings at the greater than 15 years of education level, as were communication skills self-reports at the 14 years of education level. Students with 15 years of education revealed no statistically significant correlations.

Overall, the results revealed low correlations between student self-ratings and selfconcept by years of education. The coefficient of determination for the highest correlation $\mathrm{r}$ $=0.50$ (for those with $>15$ years of education for mathematics skills) was $25 \%$. That is, $75 \%$ of the variance between student self-concept and self-ratings was unexplained.

Of the 80 students who completed instruments, 78 provided their ethnicity (see Table 5). Of those reporting their ethnicity, 19 were African American, 48 were Caucasian, and 11 were of other ethnic backgrounds. The "other" category was comprised of two Asian Americans, one Native American, four Hispanics, and three nonspecific ethnicities. Due to the small numbers in each category, the "other" designation was used.

Table 5

Correlations Between Generalizable Skills Self-Ratings and TSCS:2 by Ethnicity

\begin{tabular}{|c|c|c|c|c|c|c|c|}
\hline \multicolumn{8}{|c|}{ Generalizable Skills } \\
\hline & \multicolumn{3}{|c|}{ Mathematics Skills } & & \multicolumn{3}{|c|}{ Communication Skills } \\
\hline & Af Am & Cauc & Other & & Af Am & Cauc & Other \\
\hline TSCS:2 & & & & TSCS:2 & & & \\
\hline Physical & -0.38 & 0.11 & -0.06 & Physical & 0.01 & -0.18 & -0.09 \\
\hline Moral & -0.23 & -0.01 & 0.18 & Moral & -0.45 & -0.20 & -0.32 \\
\hline Personal & -0.44 & 0.18 & -0.34 & Personal & -0.26 & -0.15 & $-0.65^{*}$ \\
\hline Family & -0.06 & 0.01 & -0.54 & Family & 0.32 & -0.04 & $-0.89 * * *$ \\
\hline Social & -0.14 & 0.14 & $-0.67 *$ & Social & $-0.47 *$ & -0.04 & -0.52 \\
\hline Academic & -0.37 & 0.18 & 0.13 & Academic & 0.10 & -0.12 & -0.05 \\
\hline TOTAL & -0.11 & -0.05 & -0.01 & Total & -0.16 & -0.16 & $-0.82 * *$ \\
\hline \multicolumn{5}{|c|}{ Interpersonal Skills } & \multicolumn{3}{|c|}{ Reasoning Skills } \\
\hline & Af Am & Cauc & Other & & Af Am & Cauc & Other \\
\hline Physical & -0.04 & -0.07 & -0.10 & Physical & 0.06 & -0.07 & -0.02 \\
\hline Moral & -0.04 & -0.08 & 0.21 & Moral & -0.37 & -0.22 & 0.13 \\
\hline Personal & -0.16 & -0.16 & 0.22 & Personal & -0.10 & -0.18 & -0.25 \\
\hline Family & -0.11 & 0.18 & -0.21 & Family & 0.28 & 0.03 & -0.56 \\
\hline Social & -0.06 & -0.02 & -0.10 & Social & -0.45 & -0.06 & -0.29 \\
\hline Academic & 0.01 & -0.09 & -0.04 & Academic & 0.13 & -0.15 & 0.08 \\
\hline Total & -0.11 & -0.05 & -0.01 & Total & -0.08 & -0.16 & -0.32 \\
\hline$* p<0.05$ & Am; & * $p$ & auc; $N$ & $\begin{array}{l}\text { Other } \\
0.001\end{array}$ & & & \\
\hline
\end{tabular}


$r \geq 0.70$ indicates strong correlation

The findings revealed, in some cases, ranging from almost no correlation to an $r=-0.89$, for the self-concept scales. Overall, the findings revealed low correlations between student selfratings and self-concept by ethnic group except for communication and the "other" group. The coefficient of determination for the highest correlation $r=-0.82$ (for the "other" group, communication skills) was $67 \%$. That is, for ethnicity, $67 \%$ of the variance between student selfconcept and self-ratings could be explained.

Research Question 3: Is there a relationship between students' self-concept and selfratings of generalizable skills by career and technical program?

The correlations between student self-reports and self-concept indicated considerable disparity among the three programs, Technical/Industrial Occupations, Business/Office Occupations, and Health/Human Services, which includes Family and Consumer Sciences (see Table 6). With only eight Family and Consumer Science students completing the assessments, their results were combined with a similar occupational group, Health/Human Services. This was done in an attempt to provide more statistical power. Technical/ Industrial students generally had the highest correlations $(r=0.23$ for mathematics, $r=0.18$ for communication, $\mathrm{r}=0.42$ for interpersonal skills, and $\mathrm{r}=0.17$ for reasoning skills). Business/Office and Health/ Human Service occupations had similar correlations $(\mathrm{r}=-0.02, \mathrm{r}=-0.04$ for mathematics, $\mathrm{r}=-0.23, \mathrm{r}=-0.27$ for communication, $\mathrm{r}=-0.33, \mathrm{r}=0.20$ for interpersonal skills, and $\mathrm{r}=-0.30$, $\mathrm{r}=-0.04$, for reasoning skills, respectively).

No statistically significant correlations were found. The results revealed low correlations between student self-reports and self-concept by program area. These data suggest that a low correlation between self-ratings and self-concept in one generalizable skill area may produce equally low correlations in the other areas and are consistent with previous research (Greenan, 1986, 1988; Greenan et al., 1994; Wu et al., 2002).

Table 6

Correlations Between Generalizable Skills Self-Ratings and TSCS: 2 by Program Area

\begin{tabular}{lccclccc}
\hline \multicolumn{7}{c}{ Generalizable Skills } \\
\hline \multicolumn{3}{c}{ Mathematics Skills } & & \multicolumn{3}{c}{ Interpersonal Skills } \\
TSCS:2 & T/I & B/O & H/H & T/I & B/O & H/H \\
Physical & 0.56 & 0.00 & -0.08 & Physical & 0.60 & -0.21 & 0.01 \\
Moral & -0.48 & -0.12 & -0.02 & Moral & -0.49 & -0.23 & 0.21 \\
Personal & -0.32 & -0.03 & -0.14 & Personal & 0.14 & -0.22 & 0.02 \\
Family & 0.49 & -0.05 & 0.01 & Family & 0.00 & -0.08 & 0.22 \\
Social & -0.30 & 0.14 & -0.02 & Social & 0.34 & -0.20 & 0.14 \\
Academic & 0.14 & -0.07 & 0.12 & Academic & 0.45 & $-0.41^{*}$ & 0.24 \\
Total & 0.23 & -0.02 & -0.04 & Total & 0.42 & -0.33 & 0.20 \\
\hline
\end{tabular}




\begin{tabular}{lccclccc}
\hline & $\mathrm{T} / \mathrm{I}$ & $\mathrm{B} / \mathrm{O}$ & $\mathrm{H} / \mathrm{H}$ & & $\mathrm{T} / \mathrm{I}$ & $\mathrm{B} / \mathrm{O}$ & $\mathrm{H} / \mathrm{H}$ \\
Physical & 0.32 & -0.13 & -0.27 & Physical & 0.56 & -0.08 & -0.18 \\
Moral & $-0.81^{* *}$ & -0.10 & -0.20 & Moral & $-0.73^{*}$ & -0.11 & -0.12 \\
Personal & 0.08 & -0.19 & -0.29 & Personal & 0.24 & -0.26 & -0.13 \\
Family & 0.55 & -0.11 & -0.25 & Family & 0.29 & -0.06 & 0.03 \\
Social & -0.57 & -0.04 & -0.11 & Social & -0.53 & -0.26 & 0.06 \\
Academic & $0.64^{*}$ & $-0.37^{*}$ & 0.04 & Academic & 0.43 & $-0.43^{*}$ & 0.22 \\
Total & 0.18 & -0.23 & -0.27 & Total & 0.17 & -0.30 & -0.04 \\
\hline
\end{tabular}

Note: $N=10$, T/I Technical/Industrial; $N=30, B / O$ Business/Office; $N=43$, Health/Human Service ${ }^{*} \mathrm{p}<0.05 \quad * * \mathrm{p}<0.01 \quad \mathrm{r} \geq 0.70$ indicates strong correlation

Following each section of the Generalizable Skills self-assessment, the students were prompted to write comments about their generalizable skills. Twenty-one students provided comments on their mathematics skills. Of this total, seven were from business/office occupations, 12 were health/human services occupations, and two were trade/industrial students. Eleven students provided positive feedback and five students provided negative feedback with respect to their mathematics skills. Three students analyzed their weakness as the time it takes them to perform mathematics problems. Two found their weakness to be related to metric problems. One student attributed his/her learning problems with mathematics to a learning disability.

Fifteen students provided comments about their communication skills. Of these students, five were from business/office occupations and ten were from health/human service occupations. Eight comments were positive and one was negative. Three students' comments related their inability to communicate to a disability. One student analyzed his/her note-taking ability as problematic. Another student disliked making eye contact when speaking with certain people because it made the student feel uncomfortable and nervous.

Nine responses commented on students' interpersonal skills. Three students from business/office occupations and six from health/human services provided comments. Seven of nine comments were positive in nature. The other two comments provided insight into the students' interpersonal skills and abilities.

Regarding reasoning skills, four students from business/office occupations and five students from health/human services occupations responded. Six students noted positive comments regarding their reasoning skills. One student commented that this was his/her weakest area. Two students provided details and examples of their reasoning abilities. Two individuals stated that they were very task-oriented.

In total, of the 83 students providing usable assessments, 54 open-ended responses were reported. Students from the health/human services occupations were the most responsive with 
33 responses. Business/office occupations students provided 19 comments. Students in the technical/industrial occupations reported only two comments.

\section{Discussion}

The findings revealed, for the most part, low correlations between student self-ratings and self-concept in the four generalizable skill areas. Among the four areas, interpersonal skills had the highest correlations. This was consistent with the findings of Greenan et al. (1994) who suggested that interpersonal relations skills might be associated with self-concept. Student selfratings and self-concept also varied by gender, age, years of education, ethnicity, and program area. Some of these differences, for example, gender, age, and ethnicity, may be due to traditional social expectations and stereotypes. Students with the most years of education revealed higher correlations in all four generalizable skill areas. Similarly, students in the Technical/Industrial program area reported higher correlations in all four skill areas. This suggested that program requirements may be a potential influence on the self-concept of the adult learner. These findings may imply that the two instruments do not appear to measure the same constructs, thereby, reinforcing the theory that self-concept is multifaceted (Greenan, 1994). The results of this study point to the apparent multidimensional nature of self-concept.

Educators and others who intend to use either of these instruments must be cognizant of the fact that students of any age must have a sufficient level of self-awareness. Self-report measures also require substantial verbal competency, a skill that cannot be presumed. Also, some responses are more socially acceptable than others and the accuracy of self-reports is often decreased by this "social desirability" response tendency (Strein, 1995).

The goal of career and technical education is to prepare individuals to be self-sufficient, productive members in society. Clearly, a successful employee should possess generalizable skills that include mathematics, communications, interpersonal relations, and reasoning skills. The assessment of generalizable skills is a necessary requirement for providing effective and successful instruction. Approaches to assessment can include the direct assessment of skills and the indirect assessment of skills in which students are asked to rate their levels of competence. Authentic assessment requires students to demonstrate their grasp of knowledge and skills by creating a response to questions or a product that demonstrates understanding (Rojewski, 2002).

Since completion of self-ratings instruments is accomplished more quickly than performing skills, educators may choose to use ratings instruments instead of performance assessments. It is, however, important to establish if students' self-ratings reveal the same information as do performance assessments. If career and technical educators could have better access to reliable and valid procedures for measuring generalizable skills, they could more easily integrate these skills in their instruction, as appropriate (Loeding \& Greenan, 1999).

As is the case in most research studies, this study had several limitations. The generalizability of the findings of this study, therefore, are limited by several factors, including the size of the sample. The relatively small sample size and single site for this research limit the extent to which the findings can be generalized. A small but representative sample of programs was chosen. This study did not include all types of career and technical programs at the 
postsecondary college level. The population was limited to those students who were enrolled in specific career and technical programs at one area postsecondary community college. Many programs other than those selected in the four areas (Technical/ Industrial, Business/Office, Family and Consumer Sciences, and Health/Human Services occupations) were not included in this study. Additionally student self-concept, as operationally defined by the TSCS:2, may or may not represent the whole self-concept. Further, there were limitations with respect to the statistical analysis used in this study. Upon examination of the moderator variables, some of the groups were small which reduced the power and the confidence level of the findings. The small number of subjects suggested that large differences were required in order for statistical significance to occur. Therefore, caution is exercised to generalize the findings of this study to other postsecondary career and technical programs. Although the study had these practical limitations, they did not necessarily diminish the methods used or the findings and conclusions reported.

To prepare students for high-need, high-skill, and high-wage careers, career and technical educators must consider the rapidly changing nature of work and skills required in virtually all areas of the workforce. Employees must attain both higher levels of education and different forms of education, with an increasing focus on higher-order competencies such as problem solving, communication, and critical thinking skills (Jacobs \& Grubb, 2003).

The rationale, procedures, and instruments used in this study should be applicable and useful in future research in a variety of educational settings, populations, and samples. Furthermore, based on the results and in light of the limitations of this study, the following recommendations are offered for future research and practice:

1. Self-concept theory explains that self-concept is multi-dimensional, shaped by an individual's experiences, and impacts his/her future experiences. Future research should include and examine other constructs and subscales of Self-Concept.

2. Research with additional postsecondary career and technical education populations and samples is needed to further explore the relationship between Generalizable Skills Student Self-Ratings Assessment and other measures of selfconcept such as Marsh's "Self-Description Questionnaire I, II, or III” (Marsh, 1992).

3. Replication of this study in different geographic regions with larger samples of students is highly recommended. It would enable the results to be more readily generalized to other similar populations. In addition, it would further enhance the reliability and validity of the instruments.

4. Although the findings from this study aid in further validation of the Generalizable Skills Self-Ratings Assessment instruments, additional research should be conducted to examine the nature of the association between the selfratings and the TSCS: 2 .

5. Educators should be aware that adult student self-concept in postsecondary education is shaped by past academic activities (Gigliotti \& Gigliotti, 1998; Swan, 1977). In postsecondary career and technical programs, educators may use the Generalizable Skills Student Self-Ratings assessments instruments or the TSCS:2. 
However, they need to be cognizant of the differing foci of these two instruments and the outcomes and information they yield.

6. Although it is not a test of academic ability, but rather an assessment of achievement, educators should become familiar with the results of students' generalizable skills assessments so that they can provide accurate and timely feedback to students regarding their learning strengths and limitations. Educators can then integrate instruction related to those skill areas for which learners possess less proficiency. Students should be aware of the importance of each generalizable skill area in the work setting, thereby, motivating them to improve their skills.

7. Some moderator variables had very low numbers of subjects. For example, students whose age was less than 20 years consisted of four students. Students who had less than 13 years of education totaled eight subjects. Also, only four career and technical education program areas were represented and, because of low subject numbers, were combined into three areas. Future studies should include larger numbers of subjects and additional program areas to enhance statistical and practical significance.

8. Educators should be aware that self-ratings may not actually assess and reveal what they intend in the classroom; therefore, instructors and other educators should use them in combination with performance assessments and interpret the results, accordingly.

9. The results of student self-ratings can be used in career counseling activities with students. For example, they can be used to enable learners to become more aware of their skills and to assist students to identify their learning needs.

10. Schools and employers must collaborate to ensure that their communities compete in economic development. Assessing and improving generalizable skills is an important way to ensure that the United States remains competitive in the world economy.

\section{REFERENCES}

Barker, S. (2004). Improving interpersonal job skills by applying cross-cultural training. Journal of European Industrial Training. 28(2/3/4), 215-233.

Bourn, K. (1976, October). Self-concept development for high-risk students in the community college. Paper presented at the Annual meeting of the College Reading Association, Miami, FL. (ERIC Document Reproduction Service No. ED 129394)

Boyette, J. H., \& Conn, H. P. (1991). Workplace 2000: The revolution reshaping American business. New York: Dutton.

Carnevale, A., Gainer, L. J., \& Meltzer, A. S. (1990). Workplace basics: The essential skills employers want. San Francisco: Jossey Bass.

Coplin, B. (2003). Using college (and even high school) to get the skills employers want. Retrieved June 22, 2004. 
Dembo, M. H. (1994). Applying educational psychology in the classroom (5 $5^{\text {th }}$ ed.). Boston: Allyn \& Bacon.

Fitts, W. H., and Warren, W. L. (1996). Tennessee self-concept scale, TSCS:2 (2 ${ }^{\text {nd }}$ edition)[manual]. Los Angeles: Western Psychological Services.

Gardner, P. D. (2004). Recruiting trends, 2003-2004 (Michigan State University Career Services and Placement). Executive summary retrieved July 23, 2004.

Greenan, J. P. (1982). The development of generalizable skills instruments for identifying the functional learning abilities of students in vocational programs. Journal of Industrial Teacher Education, 19(4), 19-36.

Greenan, J. P. (1983). The utility of student self-ratings and teacher ratings for assessing students' generalizable skills. Community/Junior College Quarterly of Research and Practice, 7, 231-252.

Greenan, J. P. (1984). The development and validation of generalizable mathematics skills assessment instruments. Journal of Vocational Education Research, 9(3), 14-30.

Greenan, J. P. (1986). The relationship between student self-ratings and teacher ratings of students' generalizable mathematics skills in vocational programs. Journal of Industrial Teacher Education, 24(1), 47-55.

Greenan, J. P. (1988). The correlation between student self-ratings and teacher ratings of generalizable communication skills. Occupational Education Forum, 16, 9-13.

Greenan, J. P. (1994). The educational reform movement and school-to-employment transition of youth. In A. J. Paulter, Jr. (Ed.), High school to employment transition: Contemporary issues (31-46). Ann Arbor, MI: Prakken Publications, Inc.

Greenan, J. P., \& McCabe, C. C. (1989). Development and validation of generalizable reasoning skills assessment strategies and procedures. Journal of Industrial Teacher Education, $26(3), 38-50$.

Greenan, J. P., \& Sitlington, P. L. (1987). The role of generalizable skills in the vocational assessment of special needs learners. Journal of Industrial Teacher Education, 25(1), 52-59.

Greenan, J. P., \& Winters, M. R. (1989). The relationship between student self-ratings and teacher ratings of vocational students' interpersonal relations skills. Journal of Studies in Technical Careers, 11, 111-118. 
Greenan, J. P., Wu, M., Munn, K., \& Robson, E. (1994). Relationship between self-concept and self-ratings of students in vocational programs. Journal of Industrial Teacher Education, 31(2), 94-110.

Jacobs, J., \& Grubb, W. N. (2003, March). The federal role in vocational-technical education. Community College Research Center CCRC Brief, No. 18. (ERIC Education Resources Information Center ED 475560)

Loeding, B., \& Greenan, J. P. (1999). Relationship between self-ratings by sensory impaired students and teachers' ratings of generalizable skills. Journal of Visual Impairment \& Blindness, 93, 716-727. Retrieved March 18, 2003.

Lunscombe, A., \& Riley, T. L. (2001). An examination of self-concept in academically gifted adolescents: Do gender differences occur? Roeper Review, 24, 20-23.

Lynch, R. L. (2000). New directions for high school career and technical education in the $21^{\text {st }}$ century. ERIC Clearinghouse on Adult, Career, and Vocational Education Information Series No. 384. Retrieved July 1, 2002.

Marshall, C., \& Rossman, G. B. (1999). Designing qualitative research (3 ${ }^{\text {rd }}$ ed.). London: Sage Publications.

Mikulecky, L. (1987). Training for job literacy demands: What research applies to practice. Bloomington, IN: Indiana University.

Nedrow, C. (2002). Preparation for world of work (University of Northern Iowa Office of the Provost and Vice President of Academic Affairs). Retrieved July 22, 2004.

Patton, M. Q. (2002). Qualitative research and evaluation methods ( ${ }^{r d}$ ed.). Thousand Oaks, CA: Sage Publications, Inc.

Pearlman, K. (1997). Twenty-first century measures for twenty-first century work. In A. Lesgold, M. J. Feuer, \& A. M. Black, (Eds.), Papers and Proceedings. Transitions in work and learning: Implications for assessment (pp.136-179). Washington, DC: National Academy Press.

Resnick, L. B. (1997). Getting to work: Thoughts on the function and form of the school-to-work transition. In A. Lesgold, M. J. Feuer, \& A. M. Black, (Eds.), Papers and Proceedings. Transitions in work and learning: Implications for assessment (pp.249-263). Washington, DC: National Academy Press.

Rojewski, J. W. (2002). Preparing the workforce of tomorrow: A conceptual framework for career and technical education. Journal of Vocational Education Research, 27(1), 7-35. 
Secretary's Commission on Achieving Necessary Skills [SCANS], U. S. Department of Labor. (1991). What work requires of schools: A SCANS report for America 2000. Washington, DC: U.S. Government Printing Office.

Skaalvik, E. M., \& Rankin, R. J. (1990). Math,verbal, and general academic self-concept: The internal/external frame of reference model and gender differences in self-concept structure. Journal of Educational Psychology, 82, 546-554.

Strein, W. (1995). Assessment of self-concept. ERIC Digest. Retrieved August 17, 2002.

Super, D .E. (1963). Self concepts in vocational education. In D. E. Super, R. Starishevsky, N. Matlin, \& J. P. Jordaan (Eds.), Career development: Self-concept theory (Essays in vocational development)(pp 1-32). New York: College Entrance Examination Board.

Wenrich, R. C., Wenrich, J. W., \& Galloway, J. D. (1988). Administration of vocational education. Homewood, IL: American Technical Publishers, Inc.

Wu, M., Chenghsien, L., Greenan, J. P., \& Mustapha, R. B. (2002). Reasoning skills among college students in vocational and technological programs in Tiawan. VirTEC Journal, 2(2), 1-16.

Wu, M., \& Greenan, J. P. (2003). The effects of a generalizable mathematics skills instructional intervention on the mathematics achievement of learners in secondary CTE programs. Journal of Industrial Teacher Education, 40(20). 23-50. 